\title{
Originals
}

\section{Preservation of the anomeric specificity of glucose-induced insulin release in partially pancreatectomized rats}

\author{
V.Leclercq-Meyer, F. Malaisse-Lagae, V.Coulic, A. G. Akkan, J. Marchand and W.J.Malaisse \\ Laboratory of Experimental Medicine, Erasmus Medical School, Brussels Free University, Brussels, Belgium
}

\begin{abstract}
Summary. Attenuation, suppression or even inversion of the normal preference of glucose-stimulated insulin release for the $\alpha$-anomer of the hexose was recently proposed to represent a feature of Beta-cell glucotoxicity in Type 2 (noninsulin-dependent) diabetes mellitus. Since recent reports emphasize the possible significance of Beta-cell secretory hyperactivity as a determinant of such a glucotoxicity, the anomeric specificity of glucose-induced insulin release was examined in normoglycaemic partially pancreatectomized rats. About $80-85 \%$ of the pancreas was removed, the animals then being given sucrose via their drinking water up to
\end{abstract}

the time of killing. In these animals, $\alpha$-D-glucose was more efficient than $\beta$-D-glucose in stimulating insulin release from the perfused pancreas, the $\alpha / \beta$ ratio in insulin output not being significantly different from that found in control rats. It is concluded, therefore, that the anomeric malaise, taken as a manifestation of Beta-cell glucotoxicity, it attributable to hyperglycaemia rather than to Beta-cell secretory hyperactivity.

Key words: Insulin release, anomeric specificity, partial pancreatectomy.
In Type 2 (non-insulin-dependent) diabetic patients and in several experimental models of Type 2 diabetes, aparadoxical and transient fall in insulin output and a perturbation of the anomeric specificity of insulin release are often observed in response to a rapid rise in extracellular D-glucose concentration [1]. It was recently proposed that these two secretory anomalies represent manifestations of Beta-cell glucotoxicity and may be attributable, at least in part, toglycogen accumulation in the Beta cell, as a function of the severity and duration of chronic hyperglycaemia $[1,2]$. However, recent studies conducted in either cultured pancreatic islets [3] or the perfused pancreas [4] have led to the proposal that the phenomenon of Beta-cellglucotoxicity mightbe largely attributable to sustained hypersecretion of insulin rather than to hyperglycaemia. These apparently conflicting viewsled us toexamine whether the anomericspecificity of glucose-induced insulin release is also perturbed in normoglycaemic rats subjected to a partial pancreatectomy whowere, thereafter, given free access to a sucrose solution instead of drinking water, in order to impose an increased secretory strain on remaining pancreatic Beta cells.

\section{Materials and methods}

\section{Animals}

Female Wistar rats (Proefdierencentrum, Heverlee, Belgium) fed ad libitum were used in the present studies. Their body weight, plasma glucose and plasma insulin concentrations at the time of the perfusion experiments are given in Table 1.

\section{Partial pancreatectomy}

Female rats approximately 2 months old, with a body weight of $204 \pm 2 \mathrm{~g}(n=21)$, were anaesthetized with sodium barbital $(60 \mathrm{mg} / \mathrm{kg}$, i.p.), supplemented with ether when necessary. The splenic portion as well as the major duodenal part of the pancreas was removed by electrical cauterization, care being taken not to damage the pancreatic duct and the blood vessels running along the stomach and duodenum. About 80 to $85 \%$ of the pancreas was thought to be removed in the operated animals. Upon complete recovery (4-13 days), the partially pancreatectomized rats (PPX) were given sucrose via their drinking water. Perfusion experiments were performed 48 to 211 days (mean $\pm S E M ; 150 \pm 13$ days) after partial pancreatectomy. At that time, they had been drinking $40 \%$ sucrose (weight/volume) for 1 to 6.5 months.

\section{Perfusion procedures}

Both the normal and the PPX-rats were anaesthetized with sodium barbital ( $42 \mathrm{mg} / \mathrm{kg}$, i. p.) and the pancreas was perfused through both the coeliac and superior mesenteric arteries via a cannula inserted into the aorta, all adjacent organs being excluded (spleen, stomach, duodenum) by means of appropriately placed ligatures [5].

The perfusion medium contained the following salts (in $\mathrm{mmol} / \mathrm{l}$ ): $\mathrm{NaCl}, 131.9 ; \mathrm{KCl}, 4.7 ; \mathrm{KH}_{2} \mathrm{PO}_{4}, 1.2 ; \mathrm{MgSO}_{4}, 1.2 ; \mathrm{CaCl}_{2}, 2.0 ; \mathrm{NaHCO}_{3}$, 13.4. It was supplemented with dextran ( $40 \mathrm{~g} / \mathrm{l}$, clinical grade, Sigma, St.Louis, Mo, USA), bovine serum albumin ( $5 \mathrm{~g} / \mathrm{l}$, fraction V, RIA grade, Sigma) and L-leucine (10 mmol/l), and equilibrated against $\mathrm{O}_{2}$ and $\mathrm{CO}_{2}$ (95:5) with a resulting $\mathrm{pH}$ of 7.4. A finite volume of water was omitted from the basal perfusate in order to adjust the final flow rate (Minipuls peristaltic pump; Gilson, Villiers le Bel, France) through the side-arm infusion of $0.075 \mathrm{ml} / \mathrm{min}$ (glass syringes, infusion pump Unita I; Braun, Melsungen, FRG) of either 
Table 1. Metabolic status of control and PPX-rats. The basal insulin output was computed from 35 to 40 min

\begin{tabular}{|c|c|c|c|c|}
\hline & & $\begin{array}{l}\text { Control } \\
(n=6)\end{array}$ & $\begin{array}{l}\text { Partial } \\
\text { pancreatectomy } \\
(n=21)\end{array}$ & $p$ \\
\hline Plasma glucose $\mathrm{e}^{\mathrm{a}}$ & $(\mathrm{mmol} / \mathrm{l})$ & $7.1 \pm 0.4$ & $7.9 \pm 0.1$ & NS \\
\hline Plasma insulin $^{a}$ & $(\mu \mathrm{U} / \mathrm{ml})$ & $55.8 \pm 5.6$ & $94.5 \pm 6.4$ & $<0.01$ \\
\hline Rat weight & $(\mathrm{g})$ & $254 \pm 14$ & $313 \pm 12$ & $<0.05$ \\
\hline Pancreas insulin content & $\begin{array}{l}(\mu \mathrm{g}) \\
(\mu \mathrm{g} / \mathrm{g})\end{array}$ & $\begin{array}{r}98.5 \pm 18.1 \\
141.8 \pm 23.7\end{array}$ & $\begin{array}{c}59.9 \pm 6.5 \\
311.7 \pm 24.2\end{array}$ & $\begin{array}{l}<0.02 \\
<0.01\end{array}$ \\
\hline Basal insulin output & (ng/min) & $0.06 \pm 0.01$ & $0.40 \pm 0.09$ & NS \\
\hline Flow rate & $\begin{array}{l}(\mathrm{ml} / \mathrm{min}) \\
(\mu \mathrm{min} \text { per mg wet wt. })\end{array}$ & $\begin{array}{l}1.36 \pm 0.08 \\
1.98 \pm 0.12\end{array}$ & $\begin{array}{l}0.47 \pm 0.02 \\
2.78 \pm 0.26\end{array}$ & $\begin{array}{l}<0.001 \\
\mathrm{NS}\end{array}$ \\
\hline
\end{tabular}

Values observed a prior to anaesthesia and ${ }^{b}$ at the end of the perfusion surgical procedures

water alone (non-stimulatory periods) or water containing the $\alpha$-or $\beta$-anomers of D-glucose (stimulatory periods). The anomers freshly dissolved and maintained in iced solutions were administered (final concentration of $3.3 \mathrm{mmol} / \mathrm{l}$ in the perfusate) at a 20 -min interval for $15 \mathrm{~min}$ (40.5-55.5 $\mathrm{min}$ or 75.5-90.5 min) in either the $\alpha_{1}-\beta_{2}$ sequence or in the $\beta_{1}-\alpha_{2}$ sequence (three normal and seven PPX-rats in each case). Perfusions using PPX-rats were also performed in which equilibrated $D$-glucose prepared in an iced solution was administered twice at comparable times and concentrations $(n=7)$. Because of the smaller amount of pancreatic tissue present, the flow rate was adjusted to a lower value in the PPX-rats than in the normal animals (Table 1).

After an initial equilibration period, the pancreatic effluent was collected at $25,30,34 \mathrm{~min}$ and thereafter at 1 -min intervals from the portal vein into polystyrene plastic tubes containing aprotinin (1000 kallikrein inhibitor units/ml, Trasylol, Bayer, Brussels, Belgium) and EDTA (3.2 mmol/1). The effluent samples were collected with a fraction collector (Retriever II; Isco, Lincoln, Neb., USA) and immediately placed in an iced water bath. The pressure was recorded throughout the perfusions by means of a blood pressure transducer and amplifier (Palmer, London, UK). At the end of the perfusion, the pancreas was dissected free from surrounding fat and ganglionic tissues, weighed, and extracted using acidified ethanol and a mechanical homogenizer (Potter S, Braun). Both the effluent samples and the pancreas extracts were frozen at $-25^{\circ} \mathrm{C}$ until time of assay.

\section{Hormone and glucose deterninations}

The insulin concentration in the pancreatic effluent and extracts was estimated with charcoal-dextran radioimmunoassay methods as previously described [6]. The sensitivity as well as the intra- and inter-assay precision of this assay have been reported previously [7].

The glycaemia was measured in blood, collected between 09.00 and 10.00 hours from the tail of fed animals, using test strips (Meditest glucometer, Labaz-Sanofi, Brussels, Belgium). The plasma glucose concentrations were estimated by a hexokinase method (Sigma Diagnostics, St. Louis, Mo, USA).

\section{Calculations}

The mean absolute values for insulin obtained in either the $\alpha_{1}-\beta_{2}$ or $\beta_{1}-\alpha_{2}$ sequences and when equilibrated glucose was given twice were first established (Figs. 1 and 2 ). The anomeric specificity of insulin release was evaluated by calculating the $\alpha_{1} / \beta_{2}$ and $\beta_{1} / \alpha_{2}$ ratios, as judged from the area tinder the curve during exposure to each anomer (41-55 min or 76-90 $\mathrm{min}$ ) and after correction for the corresponding basal output (35-40 $\mathrm{min}$ or $70-75 \mathrm{~min}$ ). In the case of equilibrated glucose, the first/second stimulus ratios were calculated in evaluating the areas under the curve in a comparable manner.

\section{Statistical analysis}

The statistical analysis of secretory ratios was conducted on geometric rather than arithmetic means. Therefore, the range defined by the SEM was not equal on each side of the mean ratios (Fig. 3).

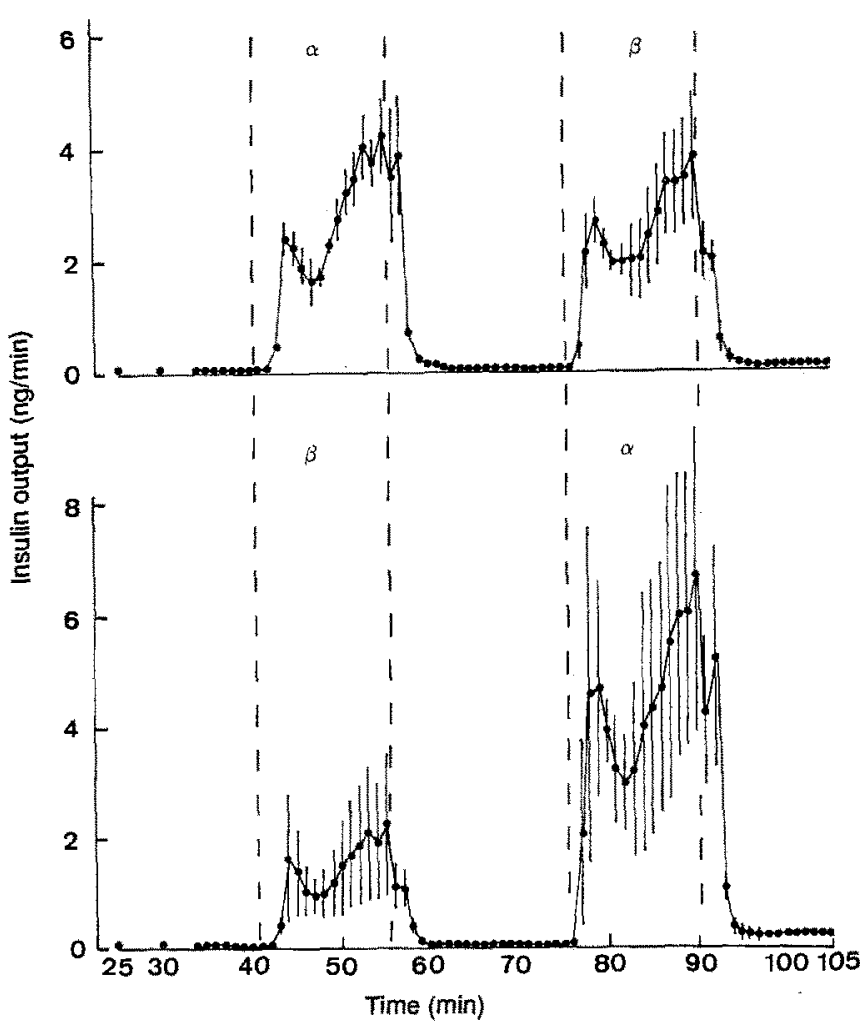

Fig. 1. Insulin release evoked by $\alpha$ - and $\beta$-D-glucose in the pancreas of control animals. Mean values ( \pm SEM) refer to three individual experiments in each case 


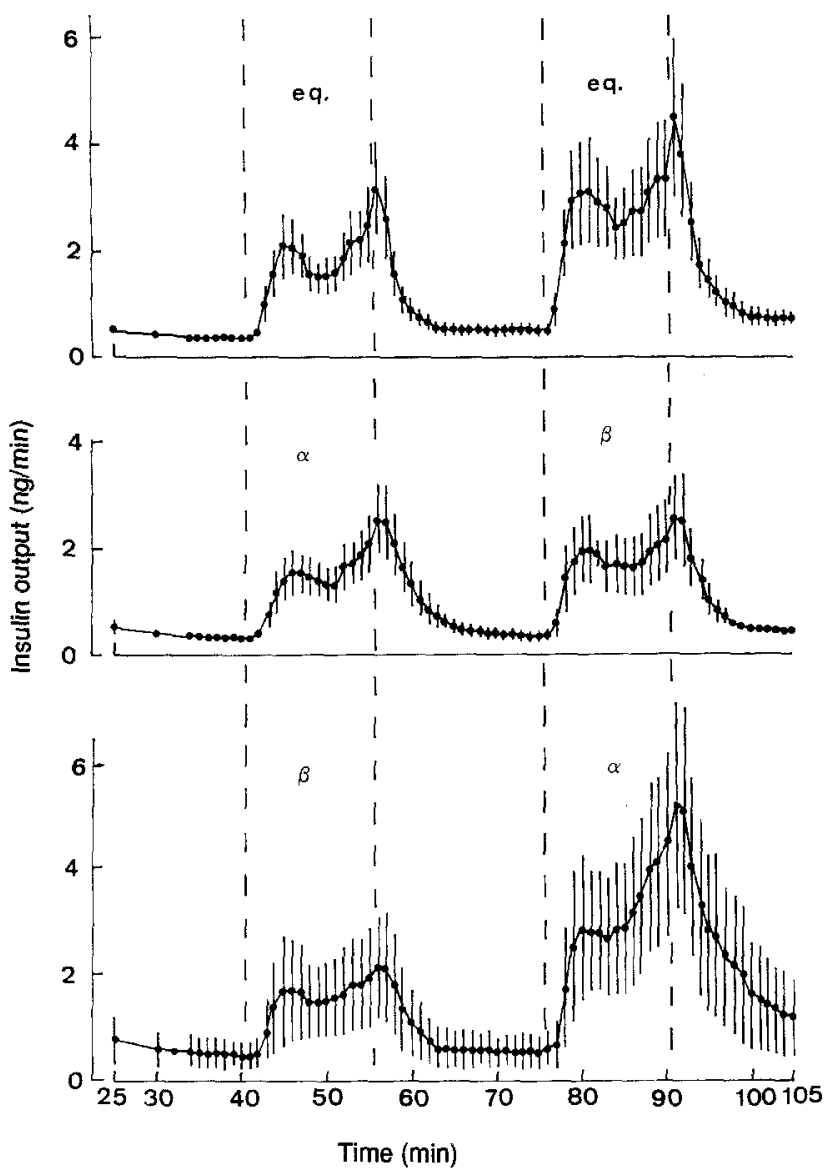

Fig. 2. Insulin release evoked by either equilibrated D-glucose (eq.) or its $\alpha$ - and $\beta$-anomer in the pancreas of partially pancreatectomized (PPX)-rats. Mean values ( \pm SEM) refer to seven individual experiments in each case

Nevertheless, for the sake of simplicity, only one SEM is given in the text together with each geometric mean. The SEM quoted in the text represents the mean of the upper and lower deviation from the geometric mean. The insulinotropic efficiency of $\alpha$-D-glucose relative to $\beta$-D glucose $(\alpha / \beta)$ was judged from the square root of the quotient obtained after division of the mean $\alpha_{1} / \beta_{2}$ ratio by the mean $\beta_{1} / \alpha_{2}$ ratio, according to the following logarithmic equation:

$\log (\alpha / \beta)=0.5 \times\left[\log \left(\alpha_{1} / \beta_{2}\right)-\log \left(\beta_{1} / \alpha_{2}\right)\right]$

All the results in the text, Table 1 and Figures are presented as the mean $( \pm$ SEM) together with the number of individual determinations $(n)$. The statistical significance of differences between mean values was assessed by use of the two-tailed Student's $t$-test.

\section{Results}

\section{Metabolic status of the PPX-rats}

The body weight of PPX-rats increased from $204 \pm 2 \mathrm{~g}$ prior to partial pancreatectomy to $313 \pm 12 \mathrm{~g}(n=21$ in both cases) prior to pancreatic perfusion. In these animals, the daily body weight gain averaged $0.73 \pm 0.06 \mathrm{~g}$ $(n=21)$. When the weight gain of PPX-rats given access to a sucrose solution was compared over close-to-equal periods of time ( $245 \pm 6$ days) to that of control rats, it was found to be slightly, but not significantly $(p<0.07)$ higher in PPX-rats $(0.57 \pm 0.05 \mathrm{~g} /$ day; $n=6)$ than control animals $(0.40 \pm 0.06 \mathrm{~g} /$ day; $n=4)$.

The glycaemia of the rats averaged $6.6 \pm 0.1 \mathrm{mmol} / \mathrm{l}$ $(n=20)$ prior to partial pancreatectomy and was slightly increased $p<0.05)$ to $7.2 \pm 0.2 \mathrm{mmol} / \mathrm{l}(n=21)$ on the day of the perfusion experiment. As shown in Table 1, the plasma glucose concentration 1-2 min prior to anaesthesia was also slightly, albeit not significantly, higher in the PPX-rats than control animals. At the end of the surgical procedure, however, the plasma glucose concentration was more markedly increased in PPX-rats than control animals. The plasma insulin concentration was much higher in PPX-rats than control animals. Both the wet weight of the pancreas and its insulin content were markedly decreased in the PPX-rats. However, when the insulin content was expressed per $g$ of pancreatic tissue, higher values were recorded in the PPX-rats than control animals. In this context, it may be noted that the weight of the remaining pancreatic tissue in PPX-rats represented, at the time of perfusion, approximately $27 \%$ of that of control rats. This suggests that the weight of the pancreatic remnant increased after partial pancreatectomy, since 80 to $85 \%$ of the pancreas was thought to be removed at the time of the initial surgery.

The pressure values recorded during pancreas perfusion were essentially comparable in PPX-rats and control animals. The flow rate was selected to be much lower in PPX-rats than control animals. When expressed relative to the weight of the pancreatic tissue, the flow rate was not

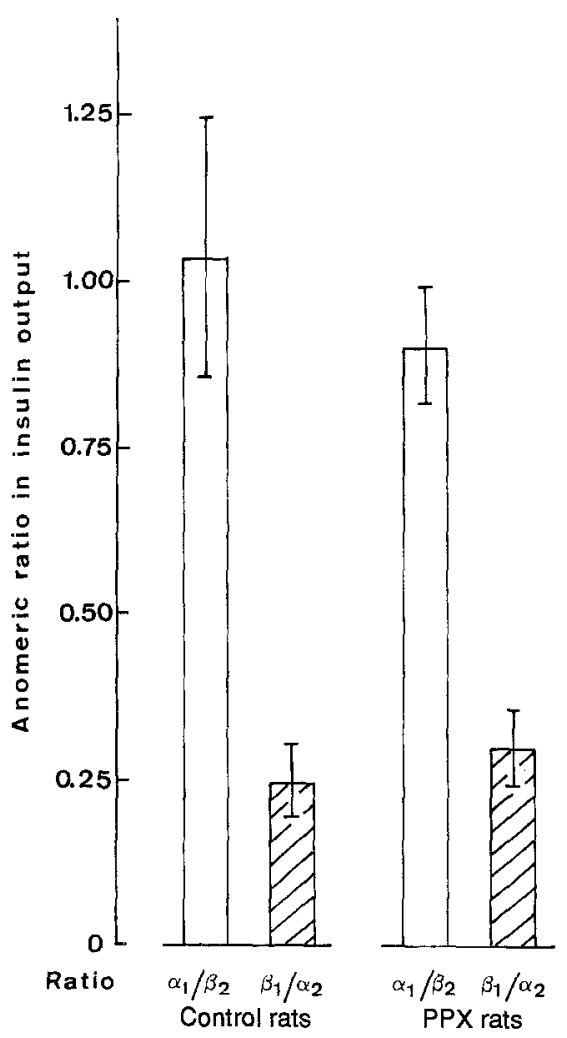

Fig. 3. Paired $\alpha_{1} / \beta_{2}$ and $\beta_{1} / \alpha_{2}$ ratios for glucose-stimulated insulin release in control rats and partially pancreatectomized (PPX)-rats. Geometric mean values ( \pm SEM) refer to three individual experiments in control rats and seven individual experiments in PPX-rats 
significantly different $(p>0.1)$ in the two groups of animals (Table 1).

\section{Secretory data}

Prior to the first administration of D-glucose, the output of insulin recorded in the sole presence of L-leucine $(10 \mathrm{mmol} / \mathrm{l})$ was higher in PPX-rats than control animals (Table 1). However, because of one unusually high reading in a PPX-rat, such a difference failed to achieve statistical significance.

The administration of $\mathrm{D}$-glucose $(3.3 \mathrm{mmol} / \mathrm{l})$ provoked a biphasic stimulation of insulin release, whether in the control animals (Fig. 1) or PPX-rats (Fig. 2). Pooling all available data, i.e. those collected with either each anomer or equilibrated D-glucose, the secretory response to the hexose, after correction for the corresponding prestimulatory insulin output, averaged $2.47 \pm 0.55 \mathrm{ng} / \mathrm{min}$ $(n=12)$ in controls rats and $1.49 \pm 0.24 \mathrm{ng} / \mathrm{min}(n=42)$ in PPX-rats. These values were not significantly different from one another $(p<0.08)$. When the same data were expressed relative to the insulin content of the pancreas, the results were quite similar $(p>0.6)$ in control animals $\left(24.4 \pm 3.610^{-6} / \mathrm{min} ; n=12\right)$ and PPX-rats $(29.1 \pm 4.8$ $10^{-6} / \mathrm{min} ; n=42$ ), respectively.

Whether in control animals or PPX-rats, an equal number of experiments included either a first administration of $\alpha$-D-glucose $\left(\alpha_{1}\right)$ and then of $\beta$-D-glucose $\left(\beta_{2}\right)$ or the opposite sequence, the administration of the $\beta$-anomer $\left(\beta_{1}\right)$ preceding that of the $\alpha$-anomer $\left(\alpha_{2}\right)$. The anomeric specificity of the secretory response was judged, therefore, from the paired $\alpha_{1} / \beta_{2}$ and $\beta_{1} / \alpha_{2}$ ratios in glucosestimulated insulin release. In the control rats, the $\alpha_{1} / \beta_{2}$ ratio largely exceeded $(p<0.01)$ the $\beta_{1} / \alpha_{2}$ ratio (Fig.3), indicating that the secretory response to $\alpha$-D-glucose was $2.05 \pm 0.32$ times higher than that evoked by $\beta$-D-glucose.

In the PPX-rats, the $\alpha_{1} / \beta_{2}$ ratio again largely exceeded $(p<0.001)$ the $\beta_{1} / \alpha_{2}$ ratio (Fig. 3 ), the secretory response to the $\alpha$-anomer being $1.75 \pm 0.19$ times higher than that evoked by the $\beta$-anomer. Such an anomeric preference was not significantly different $(p>0.4)$ from that recorded in the control rats. In the experiments including two successive administrations of equilibrated D-glucose to the pancreas of PPX-rats, the ratio between the first and second secretory response averaged $66.3 \pm 8.6 \%(n=7)$. This value was significantly lower $(p<0.02)$ than unity and, as such, documents a phenomenon of Beta-cell memory or priming. In addition, in the PPX-rats, the ratio between the first and second secretory responses to equilibrated D-glucose exceeded $(p<0.005)$ the $\beta_{1} / \alpha_{2}$ ratio and was lower, albeit not significantly $(p<0.09)$, than the $\alpha_{1} / \beta_{2}$ ratio.

\section{Discussion}

In the present study, rats were subjected to a partial pancreatectomy and were then given free access to a solution of sucrose [8] in order to impose an increased secretory demand on the remaining pancreatic Beta cells. The secretory hyperactivity of the remaining Beta cells in the PPX-rats is demonstrated by the finding that, despite the reduction in both pancreatic mass and pancreatic insulin store, the level of circulating insulin was much higher in these than in control animals. Moreover, even when excluding one abnormally high value recorded in a PPX-rat $(2.12 \mathrm{ng} / \mathrm{min})$, the mean insulin output recorded prior to the first administration of D-glucose, was significantly higher $(p<0.001)$ in the PPX-rats $(312 \pm 33 \mathrm{pg} / \mathrm{min} ; n=$ 20 ) than in the control animals $(57 \pm 14 \mathrm{pg} / \mathrm{min} ; n=6)$. The increased secretory activity of remaining Beta cells in the PPX-rats may also account for the fact that these animals remained virtually euglycaemic when examined in the fed state. A modest degree of glucose intolerance should not be ruled out, however, since the PPX-rats displayed a higher plasma glucose concentration than control animals in response to the surgical stress preceding the pancreas perfusion.

The prolonged hyperactivity of the Beta cell in PPXrats did not seem to cause any alteration of its secretory responsiveness to $\mathrm{D}$-glucose. Thus, the increment in insulin output attributable to the hexose was not lower in PPXrats than control animals, at least when expressed relative to the insulin content of the pancreas.

Despite chronic secretory hyperactivity, the Beta cells of the PPX-rats also maintained a normal anomeric specificity of glucose-induced insulin release. Thus, as judged from the anomeric ratio in insulin output from either the $\alpha_{1}-\beta_{2}$ or $\beta_{1}-\alpha_{2}$ experiments, no significant difference between PPX-rats and control animals could be found in terms of the higher insulinotropic efficiency of $\alpha-\mathrm{D}$-glucose as distinct from $\beta$-D-glucose.

The present results strongly suggest, therefore, that the anomeric malaise, considered as a manifestation of Betacell glucotoxicity $[1,2]$, is attributable to hyperglycaemia rather than to Beta-cell secretory hyperactivity. This proposal is further supported by the mirror image found in diazoxide-treated rats, in which the anomeric preference for $\alpha$-D-glucose is attenuated despite sustained inhibition of insulin release [9].

It could be argued that our PPX rats possibly displayed minimal hyperglycaemia. This would not detract, however, from the view that the anomeric malaise is tightly linked to the duration and severity of chronic hyperglycaemia [1]. Inversely, it could be speculated that a more severe degree of Beta-cell hyperactivity might cause the anomeric malaise, even in the absence of severe hyperglycaemia. The anomeric specificity of glucose-stimulated insulin release is preserved, however, in obese Zucker rats, despite marked hyperinsulinism [10].

In conclusion, the present work contributes further support to the view that sustained hyperglycaemia and its undesirable metabolic consequences in the pancreatic Beta-cell, e.g. glycogen accumulation $[1,2]$, rather than the Beta-cell secretory status, in terms of hypo- or hyperactivity, plays a key role in the perturbation of the anomeric specificity of glucose-stimulated insulin release often found in Type 2 diabetes.

Acknowledgements. This study was supported by grants from the Belgian Foundation for Scientific Medical Research and a Concerted Research Action from the French Community of Belgium. The authors are grateful to Ms. C.Demesmaeker for secretarial help. 


\section{References}

1. Malaisse WJ (1991) The anomeric malaise: a manifestation of B-cell glucotoxicity. Horm Metab Res 23: 307-311

2. Malaisse WJ (1991) Physiology of insulin secretion and its alteration in diabetes: the concept of glucotoxicity. In: Andreani G, Gueriguian JL, Striker GE (eds) Diabetic complications: epidemiology and pathogenic mechanisms. Raven Press, New York, pp 3-23

3. Svensson C, Hellerström C (1991) Long-term effect of high glucose concentration in vitro on the oxidative metabolism and insulin production of isolated rat pancreatic islets. Metabolism 40: 513-518

4. Sako Y, Grill VE (1990) Coupling of $\beta$-cell desensitization by hyperglycemia to excessive stimulation and circulating insulin in glucose-infused rats. Diabetes 39: 1580-1583

5. Malaisse WJ, Leclercq-Meyer V, Malaisse-Lagae F (1990) Methods for the measurement of insulin secretion. In: Hutton JC, Siddle K (eds) Peptide hormone secretion: a practical approach. IRL Press, Oxford, pp 211-231

6. Leclercq-Meyer V, Marchand J, Malaisse WJ (1990) Stimulussecretion coupling of arginine-induced insulin release: resistance of arginine- and ornithine-stimulated glucagon and insulin release to $\mathrm{D}, \mathrm{L}-\alpha$-difluoromethylornithine. Biochem Pharmacol 39: 537-547
7. Leclercq-Meyer V, Marchand J, Woussen-Colle M-C, Giroix M-H, Malaisse WJ (1985) Multiple effects of leucine on glucagon, insulin and somatostatin secretion from the perfused rat pancreas. Endocrinology 116: 1168-1174

8. Leahy JL, Bonner-Weir S, Weiz GC (1988) Minimal chronic hyperglycemia is a critical determinant of impaired insulin secretion after an incomplete pancreatectomy. J Clin Invest 81: 14071414

9. Leclercq-Meyer V, Marchand J, Malaisse WJ (1991) Attenuated anomeric difference of glucose-induced insulin release in the perfused pancreas of diazoxide-treated rats. Horm Metab Res 23: $257-261$

10. Leclerq-Meyer V, Marchand J, Malaisse WJ (1987) Anomeric specificity of the insulin and glucagon secretory response to D-glucose in lean and obese Zucker rats. Pancreas 2: 645-652

Received: 8 November 1991

and in revised form: 16 January 1992

Prof. Dr. W.J.Malaisse

Laboratory of Experimental Medicine

Brussels Free University

808 Route de Lennik

B-1070 Brussels

Belgium 